\title{
https://doi.org/10.30681/real.v14.4982
}

\section{CONTRAPONTO ENTRE DUAS PERSONAGENS NEGRAS DE AMOR DE MÃE}

\section{Rosana Arruda de SOUZA (UFMT)}

Resumo: Temos por objetivo fazer uma análise das personagens Vitória e Camila da novela Amor de mãe, à luz do conceito de interseccionalidade. Supomos que as personagens, interpretadas respectivamente pelas atrizes Taís Araújo e Jéssica Ellen, embora ocupem posições econômicas diferentes, dividem o mesmo lugar de opressão transpassado pela raça, gênero e condição socioeconômica, elementos basilares da interseccionalidade.

Palavras-chave: Amor de mãe. Atrizes negras. Interseccionalidade.

Abstract: We aim to make an analysis of the characters Vitória and Camila from the soap opera Mother's love, in the light of the concept of intersectionality. We assume that the characters, played respectively by the actresses Taís Araújo and Jéssica Ellen, although occupying different economic positions, share the same place of oppression crossed by race, gender and socioeconomic condition, basic elements of intersectionality.

Keywords: Mother's love. Black actresses. Intersectionality.

\section{Introdução}

Amor de mãe é transmitida no horário nobre da emissora Globo e tem se destacado por trazer vários pontos diferenciais em relação às novelas anteriores. A novela chama a atenção pela sutileza dos detalhes, da temática oferecida e de um enredo atraente sem precisar apelar para personagens e situações exageradas beirando ao sensacionalismo. Há um equilíbrio nas cenas, uma delicadeza muito bem pensada a fazer com que temas sociais e humanos como o preconceito e a opressão sejam abordados com verdade, ao menos uma verdade no sentido de causar empatia nos telespectadores.

O quadro de protagonistas da novela é composto pelas atrizes Regina Casé, Adriana Esteves e Taís Araújo, interpretando respectivamente Lurdes, Thelma e Vitória, mulheres de classes socioeconômicas diferentes, mas com algo que aproxima uma da outra: o sentimento da maternidade.

Lurdes tem 57 anos, nordestina, babá, mãe de quatro filhos de sangue, Magno, Ryan, Domênico e Érica, e uma de criação, Camila. Há 26 anos, foi para o Rio de Janeiro atrás de um dos filhos, Domênico, vendido pelo ex-marido no nordeste para uma traficante de crianças. Camila foi encontrada abandonada pelo caminho, no momento em que Lurdes saiu pela estrada rumo ao Rio de Janeiro. 
Vitória tem 42 anos, é uma advogada de sucesso e sonha em ser mãe. No entanto, ela guarda um segredo: engravidou quando era muito jovem e, com medo de que o filho atrapalhasse seus estudos e seu sonho de crescer profissionalmente, deu-o à Kátia, a mesma traficante de crianças que comprara o filho de Lurdes.

Thelma é proprietária de um restaurante e mãe superprotetora de Danilo. A superproteção ao filho se deve ao fato de ela quase tê-lo perdido em um incêndio quando ele era um bebê.

A novidade da novela aparece no fato de ela ter três mulheres protagonistas, destoando do lugar-comum em que aparece sempre um casal protagonizando, além disso, uma das protagonistas é negra, não exerce a profissão de empregada doméstica como permaneceram por muitos anos personagens negras na TV e, mais que isso, das três, ela quem ocupa um maior patamar econômico.

Nessa mesma esteira, outra personagem negra destaque na história, embora não seja protagonista, é Camila, como já dissemos, a filha de criação de Lurdes. Camila se graduou no curso de História, tornou-se professora. Ao iniciar sua profissão, ela enfrentou vários desafios, como o fato de lecionar em uma escola da periferia, próxima aos tiroteios da favela, e entrar em embate com as ideias atrasadas e preconceituosas da diretora da escola, para quem os alunos dali não tinham futuro e eram incapazes de aprender.

Por fim, a trama imita algo bem marcante na realidade de algumas mulheres que optam por ascender profissionalmente: acabam tendo de abrir mão da maternidade ou deixam isso para uma idade mais avançada. Em melhores palavras, parece que para uma mulher negra tal escolha equivale a uma obrigação: se ela quer estudar, crescer profissionalmente, tem de se esforçar mais que a mulher branca, portanto, deve ficar solteira, sem filhos; o casamento, os filhos e a ascensão profissional todos juntos seriam um privilégio apenas das mulheres brancas. A regra seria: mulher negra, se quiser crescer, tem que abrir mão, tem que se pôr à frente de seu tempo, tem que ser sempre forte e, para mostrar que é forte, enfrentar as batalhas sozinha, nada de querer construir uma família que lhe possa servir de base afetiva e emocional nos momentos de fraqueza.

Assim, temos duas personagens negras a constituírem um contraponto: de um lado, a mulher madura, em boa condição econômica, mas que como veremos, também sofrerá seus embates devido à cor da pele; de outro, Camila, a professora, como veremos, cheia de sonhos, que tem consciência de sua condição de mulher negra e de origem pobre, para quem haverá um árduo caminho pela frente. 
Como podemos observar a trama novelística está em consonância com vários fatores sociais e vários sentimentos humanos que transpassam as situações de opressão vividas pela mulher negra. Assim, a despeito de algumas pessoas abordarem as novelas como um objeto irrelevante para os estudos acadêmicos - acreditando que ela seria apenas o palco de ilusões, de coisas que jamais acontecem ou aconteceriam na realidade, sem complexidade narrativa digna de ser levada em conta em algum estudo - presenciamos não só a entrada desses objetos populares nas universidades, como também uma virada no modo de se ver e de se construir as epistemologias.

Do mesmo modo que criamos ferramentas de sensibilidade que nos permitam tomar como objetos de estudo elementos vindos do cotidiano de nossas vivências, demanda-se desendurecer certas epistemologias, ou criar novas, contra-hegemônicas.

Segundo Moita Lopes (2004), vivemos mudanças em nosso campo, as questões que estão sendo estudadas têm se modificado e os modos de estudá-las também, o que tem acarretado a redefinição de áreas de investigação, provocando desarticulações nas disciplinas, nos departamentos e nos programas (ainda que sejam pequenas e poucas no Brasil).

E se objetivamos analisar duas personagens negras de uma novela podemos pensar desde já que temos aí dois elementos não canônicos dentro do campo acadêmico: a personagem negra e a novela. Até bem pouco tempo atrás, a presença de mulheres negras ocupando os bancos das universidades era novidade; uma mulher negra ocupando o cargo de professora em universidade permanece como novidade; e mulher negra produzindo ciência, tendo reconhecimento, então, constitui algo incipiente. Do mesmo modo que falamos em poesia feminina negra, será que dá para falar em alguma epistemologia, ou uma ferramenta epistemológica feminina negra?

Sim, é possível, desde que quebremos algumas barreiras impostas dentro do próprio campo onde os conhecimentos são produzidos e reconhecidos como tal. Pretendemos analisar, de um lado, a protagonista Vitória, levando em conta que embora esteja num patamar econômico favorável, o fator raça a coloca numa fronteira instransponível. E do outro, a personagem Camila, levando em conta que a barreira a ser superada por ela vai além de sua origem pobre e de seu gênero, instala-se na cor da sua pele.

É nesse sentido que nasce a interseccionalidade dentro do feminismo negro, para dar inteligibilidade aos casos em que a opressão por se ser mulher passa pelo fator raça e, consequentemente, pelo fator socioeconômico. À luz desse conceito, far-se-á a análise pretendida. 


\section{Interseccionalidade}

Ser mulher não se submete a uma categoria universal, de maneira que qualquer situação de opressão poderá envolver uma produção de sentidos diferente a depender do espaço social e histórico onde a mulher está situada. Judith Butler adianta:

Se alguém é uma mulher, isso certamente não é tudo que esse alguém é; o termo não logra se exaustivo, não porque os traços predefinidos de gênero da pessoa transcendam a parafernália específica de seu gênero, mas porque o gênero nem sempre se constitui de maneira coerente ou consistente nos diferente contextos históricos, e porque o gênero estabelece intersecções com modalidades raciais, classistas, étnicas, sexuais e regionais de identidades discursivamente constituídas (BUTLER, 2003, p. 20).

Numa perspectiva próxima, vemos ser cunhado em 1989 o conceito de interseccionalidade pela intelectual afro-estadunidense Kimberlé Crenshaw:

a interseccionalidade visa dar instrumentalidade teórico-metodológica à inseparabilidade estrutural do racismo, capitalismo e cisheteropatriarcado produtores de avenidas identitárias em que mulheres negras são repetidas vezes atingidas pelo cruzamento e sobreposição de gênero, raça e classe, modernos aparatos coloniais (AKOTIRENE, 2019, p. 19).

Em palavras mais simples, existem determinadas situações em que nós mulheres negras passamos despercebidas dentro de um feminismo de base: de repente a violência de gênero sofrida por alguma mulher não foi por ela ser mulher, mas por ser mulher negra. É claro, isso cria um perigo de banalização do conceito, e nada impediria o mesmo ser usado dentro do feminismo de base para explicar situações em que quer se cruzar o gênero com outras características além da raça e da classe. Tomando-se como exemplo: mulher, branca e gorda não entraria na alçada desse conceito, pois ser negra não imprime uma característica física ou meramente de aparência, a interseccionalidade mexe com unidades estruturais identitárias da sociedade historicamente constituídas.

Carla Akotirene oferece outros exemplos que problematizam a interseccionalidade:

a autoclassificação do sujeito que se declara negro sendo ele branco, destoa a aplicação da interseccionalidade, porque o racismo não alcança esta experiência, por mais que se apresente de turbante, significados religiosos de candomblé, seja de classe trabalhadora, a sistemática racista não alcança esta identidade na matriz de opressão, ali, na avenida em que estruturas se articulam, simplesmente, porque o racismo está aí, como dito, há mais de 4 mil anos, há quinhentos anos mostrando a sua modernidade. Acessórios 
estéticos de negro são resolvidos quando as identidades tiram as aparências e mantêm suas peles brancas (AKOTIRENE, 2019, p. 46).

Analisar situações com um olhar interseccional se afasta do intento de criar uma zona de competição, entre mulheres brancas e mulheres negras, em que se compete para saber quem é mais oprimido. A intenção está em voltar o olhar para detalhes que vêm a agravar as situações de opressão em que a violência de gênero se cruza com o racismo sendo, portanto, necessário verificar a ambos de quando de sua análise, julgamento e compreensão.

Como bem apontam Silveira e Nardi (2014), após uma pesquisa sobre casos de violência de gênero contra mulheres: há uma sobrerrepresentação das mulheres negras nos boletins de ocorrência, nas entrevistas, mas não nos processos e, apesar disso, os/asjuízes/as entrevistados/as compreendem que a interseccionalidade não interfere no acesso à justiça. $\mathrm{Ou}$ seja, num caso de abuso contra a mulher faz diferença sim se essa mulher é negra; tal fato, ao contrário dos casos analisados por Silveira e Nardi (2014), deve aparecer nos processos jurídicos. Do mesmo modo, farão diferença os artifícios utilizados para combater a violência.

\section{Contraponto entre Vitória e Camila}

Para análise, escolhemos primeiramente a cena em que a personagem Camila está hospitalizada, depois de tomar um tiro dentro da escola em que lecionava. A jovem desabafa com a mãe os desafios desde sempre enfrentados na sociedade devido ao fato de seu gênero, de sua classe e de sua raça:

O problema é esse. Eu vou sempre ter que ser forte? Sempre? Eu tenho que ser forte porque a gente é pobre e eu quero estudar. Eu tenho que ser forte porque eu sou mulher e pra mulher tudo é mais difícil. Tem que aguentar sempre um babaca olhando pro meu peito ao invés de prestar atenção no que eu tenho a dizer.

Eu tenho que ser forte porque eu sou preta e a gente vive num país racista. Eu tenho que ser forte porque eu sou professora, porque eu tentei ajudar meus alunos e levei um tiro. Eu tô cansada, mãe! Eu tô cansada de ser forte, mãe. Eu não vou poder ser fraca nenhum dia?

No trecho acima, a situação de opressão vivenciada por Camila foge do que o feminismo por si só poderia atender. A questão não se constitui apenas pelos assédios sofridos por ser mulher. Se formos analisar bem, ser mulher, negra e pobre estaria com um grau de complexidade superior ao de ser mulher. Então, numa conversa em que você tenta expor seus argumentos para o "cara babaca que não para de olhar para o seu peito", a mulher negra, pobre 
terá três barreiras, ou dois estereótipos a mais para quebrar: primeiro tentar convencer o homem que chegamos a tal lugar sem termos precisado nos oferecer a nenhum babaca igual a ele; segundo, que a negra fala,estuda, dá aula, deixou de ocupar o lugar da empregada doméstica sexualizada; terceiro, que ela não tem dinheiro, mas tem conhecimentos e se esforçou tanto, o suficiente para ultrapassar a mulher branca que teve os melhores colégios e cursos.

A interseccionalidade nos permite ter esse olhar analítico não para criar uma competitividade de opressão, mas para verificar detalhes que talvez passassem em branco, e a personagem não deixaria de ser oprimida se tivesse seus direitos de mulher reconhecidos, feito isso, as dificuldades perdurariam e ela continuaria "tendo que ser forte" por ser negra e pobre. Para Akotirene (2019, p. 23), “o feminismo negro dialoga concomitantemente entre/com as encruzilhadas, digo, avenidas identitárias do racismo, cisheteropatriarcado e capitalismo". Essa visão vem a calhar quando focamos a fala de Lurdes, ao responder à filha:

Tu não pode fraquejar. Ainda não dá pra ser fraca. Nesse mundo que a gente vive, não dá. Eu não aguento isso: tudo você tem que ser a melhor, passar em primeiro lugar. Isso me dá raiva. Por que tem quer ser assim? Mas é assim. A gente tem que continuar assim, aproveitando cada chance da vida. Por que tem que estar o tempo todo assim? Porque a gente não é gente, não; a gente é sobrevivente.

Ainda mais pra nós, pra mulher, é muito mais difícil. Ainda mais tu, da tua cor. Como eu queria que ninguém te julgasse pela cor da tua pele. Mas ainda não dá. A gente tem que continuar empurrando o mundo, mesmo ele sendo muito pesado... Empurrando para ele mudar. Tu virou uma professora. Tá educando um monte de menino. Pra mudar o mundo. E se a gente for bem forte, a filha desse aí que tá na sua barriga vai poder fraquejar. Por enquanto não dá, não, filha.

No trecho "ainda mais pra nós, pra mulher, é muito mais difícil. Ainda mais tu, da tua cor. Como eu queria que ninguém te julgasse pela cor da tua pele", fica clara a questão da opressão por gênero vir interseccionada pelo fator raça e isso ser sim um diferencial, a tornar o "mundo mais pesado", a fazer com que lutemos para que as próximas gerações de mulheres negras encontrem um mundo mais leve. A cor de pele da personagem Camila se configura como uma diferença, dentro da própria diferença de seu gênero, e isso aparece no momento em que a mulher negra vai angariar um degrau profissional, ou um degrau acadêmico - perdura-se o desejo de Lurdes de "não querer que ninguém julgue pela cor da pele". E é utilizando a interseccionalidade que podemos observar isso, focando no tripé das outras diferenças que transpassam o gênero feminino, sem, no entanto, criar uma infinidade de marcadores que poderiam banalizar o conceito. Como bem aponta Carlos Eduardo Henning (2015), não necessariamente é preciso desenvolver a análise de uma infinidade de marcadores em toda e 
qualquer análise social, mas atentar para o entrelaçamento daqueles que se mostram relevantes contextualmente, ou seja, partindo de análises atentas às diferenças que fazem diferença em termos específicos, históricos, localizados e, obviamente, políticos.

Outra cena escolhida para ser analisada está no momento em que Camila diz para sua sogra que não quer ter filhos tão cedo:

- Olha só, dona Thelma, eu preciso ser muito sincera com a senhora, eu não pretendo ter filhos tão cedo.

- Você não falou pra mim que era louca pra ser mãe?

- Sim, mas eu tô falando de ser mãe daqui a dez anos.

- Dez anos?

- É, no mínimo, se não for mais tempo.

- Tudo isso?

- Dona Thelma, eu tenho vinte e quatro anos, eu tô começando a dar aula agora, não pretendo ter um filho tão cedo.

- É, assim, de repente nem dez anos. O que ela tá querendo dizer é que as pessoas hoje em dia têm filho mais tarde. E tudo bem, é normal. [filho de Thelma]

Na cena acima, embora o filho de Thelma amenize a situação de Camila, apontando a normalidade de se ter filhos mais tarde atualmente, como se fosse algo comum das mulheres em geral, não há como deixarmos de tecer uma ponte à realidade da mulher negra especificamente. A personagem Camila está começando a dar aula, como ela mesma diz, e estipula para si o prazo de dez anos no mínimo para enfim pensar em constituir uma família. Podemos indagar se uma mulher branca também estipularia para si tal prazo tamanho ou se estipularia algum prazo. Será que as prioridades da mulher branca seriam as mesmas que de uma mulher negra nesta situação?

Para Davis (2018, p. 79), a interseccionalidade encoraja a cada acadêmica feminista a se envolver criticamente com suas próprias hipóteses seguindo os interesses de uma investigação feminista reflexiva, crítica e responsável. Com base nesse pensamento, podemos refletir que a escolha de Camila reverbera a realidade da mulher negra: o corpo negro foi muito visto como o corpo da procriação, o corpo cuja única expectativa na vida constituía-se em parir filhos e/ou cuidar dos filhos dos outros. A escolha de Camila em querer deixar a maternidade para um futuro mais distante reverbera a própria urgência da mulher negra em se despojar do corpo sexualizado e procriador, substituindo-o pelo corpo pensante, crítico, trabalhador e profissional.

Tudo isso conferiria o que Davis (2018) chamou de investigação feminista reflexiva e crítica. Para nós, mulheres negras, não basta lançarmos mão do feminismo, pois sabemos que 
nossas demandas históricas são outras, e temos diferenças a transpassarem a nossa realidade, mas não transpassam a realidade da mulher branca. Por isso é necessário refletirmos e termos a criticidade de reconhecer que não cabemos dentro de qualquer espaço feminista; é preciso que construamos (e já estamos fazendo) o nosso espaço, com base nas nossas vivências.

A outra cena escolhida para analisarmos se refere a uma das protagonistas da novela, Vitória. Conforme já pontuado, esta mostra outro lado da mulher negra, situada em outro patamar econômico: advogada, tem como principal cliente o milionário Álvaro da Nóbrega, dono de uma empresa de plástico conhecida por burlar as leis ambientais, com dutos de rejeitos a poluir os rios e intoxicar os moradores próximos. Vitória configura uma profissional ambiciosa, defende Álvaro não o deixando nunca ser preso por suas ilegalidades, porém, quando enfim realiza o sonho da maternidade, ela revê seus conceitos e resolve quebrar o contrato com o empresário. Antes disso, observamos um momento em que a cor da sua pele vem à tona, tornando-se foco da artimanha de Álvaro, quando propõe que ela faça parte de uma fundação da empresa, por ser mulher e negra. A proposta ocorre durante um jantar da empresa:

- Se prepara, vou fazer o convite ao vivo pra você fazer parte da fundação Álvaro da Nóbrega.

- Obrigada. Muito obrigada, mas nem pensar, Álvaro. Faz esse convite pra Lídia.

- Não. Tem muito mais a ver com você.

- Comigo? Por quê?

- Esse lance da fundação adora minoria, Vitória. Você é mulher, negra, você é bem-sucedida, melhor propaganda não há. Vai por mim, ser minoria hoje em dia é o melhor capital.

- Você é imoral, né, Álvaro?!

- Amoral, eu sou amoral.

Quando Álvaro aponta o gênero e a cor de pele de Vitória dando destaque ao fato de ela constituir a minoria, fica patente o entrelaçamento de marcadores sociais e estruturais que demarcam uma diferença na situação de Vitória. Notemos que a mesma ainda pede a Álvaro o repasse da proposta à outra mulher, Lídia, mas ele frisa: "não, tem muito mais a ver com você". A proposta tem muito mais a ver com Vitória, porque além do marcador do gênero feminino, ela tem o marcador da raça. Sim, ela é mulher e bem-sucedida, mas algo a coloca na minoria, a cor da sua pele. Minoria porque ainda constitui exceção uma mulher negra chegar aonde ela chegou.

A interseccionalidade serve justamente para promover a quebra hierarquização de mulheres de quando em situações como a de Vitória. Lídia, de quem ela fala, trata-se de uma mulher branca, socialite, e a fala de Álvaro coloca Vitória automaticamente abaixo dela, ou, 
como ele mesmo diz, numa minoria. A advogada pode até se equiparar em termos de postura e elegância à socialite, além de ser uma mulher inteligente, competente em sua profissão e estar ali, no jantar da empresa, dividindo o mesmo espaço social que a primeira, mas nesse espaço ela continua sendo um pontinho a se destacar negativamente - o olhar dos outros para ela deve aproximar-se ao de Álvaro, como se estivesse ressaltando-a com o questionamento: mas você, uma mulher negra, está aqui?! - assim, Vitória continua sendo a diferença.

\section{Considerações finais}

Segundo Djamila Ribeiro (2019), ainda é muito comum dizer que o feminismo negro traz cisões ou separações, quando é justamente o contrário, ao nomear as opressões de gênero, raça e classe, entende-se a necessidade de não hierarquizar as opressões, pensar em um feminismo negro é justamente romper com a cisão criada numa sociedade desigual.

No caso das novelas televisivas, nota-se que elas também são espaço onde se constitui tal cisão: poucos atores negros; antigamente encenavam só como empregados domésticos, quando não, tinham até de passar pó no rosto para não parecerem tão escuros. Ainda que às vezes se questione a presença de atores negros como uma artimanha da emissora Globo para ampliar seu capital, equalizando a minoria como a "moda da vez" (parafraseando o personagem Álvaro) é notável, digno de sinceras felicitações, o espaço aberto por ela, uma abertura positiva, que outras emissoras não fazem. Em pleno século XXI, o que vemos em outras emissoras, por exemplo, é uma novela que ainda insiste na imagem de uma sala de aula onde apenas um aluno é negro (dado como o coleguinha fracote e bobo) e, juntamente como seu pai e sua mãe, integra o núcleo negro da novela - o "núcleo" negro, perdurando a imagem do negro como diferença.

Entendendo a linguagem como mecanismo de manutenção de poder (RIBEIRO, 2019), a mesma linguagem se manifesta nas novelas, sobretudo quando refletem as cisões da sociedade, colocando em personagens como Vitória e Camila um contraponto importante da mulher negra, com a cor de pele sempre a interseccionar suas vivências, suas conquistas, suas escolhas, suas prioridades, a despeito de ocuparem patamares econômicos distintos.

Numa visão transferencial para a realidade factual de muitas mulheres negras, a advogada negra continua sendo o pontinho destaque num jantar de um empresário milionário, do mesmo modo, configura-se a graduada, professora de história, a se perceber ainda como 
diferença e que, provavelmente, para crescer terá de se esforçar mais que todo mundo, e deixar a maternidade para mesma idade madura de Vitória. ${ }^{1}$

\section{Referências:}

AKOTIRENE, Carla. Interseccionalidade. São Paulo: Sueli Carneiro; Pólen, 2019.

BUTLER, Judith. Sujeitos do sexo/gênero/desejo. In: Problemas de gênero: feminismo e subversão de identidade. Rio de Janeiro: Civilização Brasileira, 2003. p. 17-60.

DAVIS, Kathy. Intersectionality as buzzword, a sociology of science perspective on what makes a feminist theory successful. Feminist Theory, vol.9(1), 2008, p. 67-85.

HENNING, Carlos Eduardo. Interseccionalidade e pensamento feminista: as contribuições históricas e os debates contemporâneos acerca do entrelaçamento de marcadores sociais da diferença. Mediações, Londrina, v. 20 n. 2, p. 97-128, jul./dez. 2015.

DESABAFO de Camila para Lurdes em Amor de mãe viraliza na internet. Produção: Emissora Globo de Televisão. Rio de Janeiro: Globoplay, 2019. Disponível em: https://rd1.com.br/desabafo-de-camila-para-lurdes-em-amor-de-mae-viraliza-na-web/. Acesso em: 19 fev. 2020.

MOITA LOPES, Luiz Paulo. Contemporaneidade e construção de conhecimento na área de estudos linguísticos. Scripta, Belo Horizonte, v. 7, n. 14, p. 159-171, 1º sem. 2004.

RIBEIRO, Djamila. Apresentação. In: AKOTIRENE, Carla. Interseccionalidade. São Paulo: Sueli Carneiro; Pólen, 2019.

SILVEIRA, Raquel da Silva; NARDI, Henrique Caetano. Interseccionalidade gênero, raça e etnia e a lei Maria da Penha. Psicologia \& Sociedade, 2014, v.26, p.14-24.

THELMA concorda com Camila não querer filho. Produção: Emissora Globo de Televisão. Rio de Janeiro: Globoplay, 2019. Disponível em: https://globoplay.globo.com/v/8199005/. Acesso em: 29 fev. 2020.

VINÍCIUS e Amanda envenenam jantar de Álvaro. Produção: Emissora Globo de Televisão. Rio de Janeiro: Globoplay, 2019. Disponível em: https://globoplay.globo.com/v/8237046/. Acesso em: 29 fev. 2020.

\footnotetext{
${ }^{1}$ A análise aqui apresentada foi realizada antes do término da novela, ou seja, refere-se a um determinado período dela. Com o desenrolar da trama, obviamente os personagens e suas situações, aqui referenciadas, podem ter sofrido mudanças.
} 